\title{
Tongue oximetry in children with extensive thermal injury: comparison with peripheral oximetry
}

We undertook a prospective study of standard peripheral pulse oximetry versus a modified pulse oximeter probe applied to the tongue in order to determine the efficacy of this alternative monitoring site in children with thermal injuries. Ten patients with a mean age $( \pm S D)$ of $7.5 \pm 4.5$ yr were studied on 15 occasions. The mean weight $( \pm S D)$ was $31.4 \pm 13.7 \mathrm{~kg}$ and percent surface area burn ( $\pm S D$ ) was $56 \pm 21 \%$. A total of 1,992 min of anaesthesia time was monitored. Both sites functioned simultaneously $47 \%$ of the time; the lingual but not the peripheral site functioned $28 \%$ of the time and only the peripheral site and not the lingual functioned $22 \%$ of the time. Neither site functioned $3 \%$ of the time. The tongue oximeter provided $563 \mathrm{~min}$ more monitoring time than the peripheral sites. The tongue oximeter also functioned in children with peripheral vasoconstriction when the peripheral sensor failed and was less susceptible to electrocautery interference. The tongue oximeter is a reasonable adjunct but not a substitute for peripheral oximetry since its application is limited to paralyzed, intubated patients.

Afin d'évaluer la langue comme site de monitorage de la saturation artérielle en oxygène chez des enfants brûlés, un capteur standard d'oxymètre de pouls périphérique est comparé de façon prospective à un capteur adapté à la langue. Dix

\section{Key words}

ANAESTHESIA: paediatric;

COMPLICATIONS: burnS;

MEASUREMENT TECHNIQUES: oximeters;

MONITORING: OXYgen.

From the Department of Anaesthesia, Harvard Medical School at the Massachusetts General Hospital and the Shriners Burns Institute, Boston, MA 02114.

This research was supported by an equipment grant from Nellcor, Inc., Hayward, CA.

Presented in part at the Annual Meeting, Section on Anesthesiology, American Academy of Pediatrics, 1990.

Accepted for publication 2nd February, 1992.
Charles J. Coté MD, Alfred L. Daniels MD, Michelle Connolly RN, Stanislaw K. Szyfelbein MD, Charles D. Wickens BS enfants âgés de 7,5 $\pm 4,5$ ans participent à l'étude au cours de 15 interventions. Les enfants ont un poids moyen de 31,4 \pm $13,7 \mathrm{~kg}$ et présentent des brûlures couvrant en moyenne $56 \pm$ $26 \%$ de la surface corporelle. La durée totale de la période anesthésique étudiée est de 1992 minutes. Les deux sites de monitorage sont simultanément fonctionnels durant $47 \% \mathrm{du}$ temps. Pendant une période couvrant $28 \%$ du temps étudié, le capteur au niveau de la langue permet une mesure de saturation artérielle alors que le capteur périphérique ne donne pas de signal. $\dot{A}$ l'inverse, durant $22 \%$ du temps, le capteur périphérique est fonctionnel alors que celui de la langue ne l'est pas. La période pendant laquelle les deux capteurs sont simultanément inefficaces représente $3 \%$ du temps total. Le capteur au niveau de la langue permet 563 minutes de monitorage de plus que le capteur périphérique. La mesure de la saturation artérielle au niveau de la langue est possible chez des enfants avec vasoconstriction périphérique alors qu'elle ne l'est pas avec le monitorage périphérique. De plus, le monitorage au niveau de la langue est moins sensible aux interférences électriques. En conclusion, la langue représente une alternative raisonnable comme site de monitorage de l'oxymètre de pouls. Cependant, son utilisation se limite aux patients myorelaxés et ventilés mécaniquement.

Pulse oximetry has been shown to detect hypoxaemia well before there are any clinical manifestations such as cyanosis or change in vital signs. ${ }^{1,2}$ One of the many problems associated with the anaesthetic care of children with extensive thermal injury is a satisfactory and reliable site to place a pulse oximeter probe. We therefore undertook a prospective study of peripheral versus tongue oximetry in children undergoing excision and grafting procedures using a standard pulse oximeter probe modified so that it could be atraumatically applied to the tongue. ${ }^{3}$

\section{Methods}

Children with extensive thermal injury scheduled for surgical procedures were candidates for study. This protocol was approved by the Subcommittee on Human 
TABLE Demographic data and percent functional oximeter time

\begin{tabular}{|c|c|c|c|c|c|c|c|}
\hline \multirow[b]{2}{*}{ Patient } & \multirow[b]{2}{*}{ Age $(y r)$} & \multirow{2}{*}{$\begin{array}{l}\text { Monitor } \\
\text { time }(\min )\end{array}$} & \multirow[b]{2}{*}{ \% Burn } & \multicolumn{4}{|c|}{ Functional oximeter time - percent of total time monitored } \\
\hline & & & & Tongue & Peripheral & Both & Neither \\
\hline 1 & 7 & 154 & 90 & 100 & 0 & 0 & 0 \\
\hline 2 & 5 & 90 & 60 & 88 & 100 & 88 & 0 \\
\hline 3 & 16 & 110 & 50 & 96 & 55 & 55 & 4 \\
\hline 4 & 7 & 218 & 65 & 94 & 84 & 84 & 6 \\
\hline 5 & 6 & 161 & 55 & 33 & 99 & 32 & 0 \\
\hline 6 & 3 & 125 & 40 & 48 & 100 & 48 & 0 \\
\hline 7 & 4 & 35 & 19 & 15 & 100 & 15 & 0 \\
\hline 8 & 2 & 140 & 50 & 0 & 100 & 0 & 0 \\
\hline 9 & 11 & 99 & 40 & 100 & 95 & 95 & 0 \\
\hline 9 & 11 & 172 & 40 & 100 & 55 & 45 & 0 \\
\hline 9 & 11 & 151 & 40 & 100 & 64 & 64 & 0 \\
\hline 10 & 14 & 170 & 90 & 100 & 100 & 100 & 0 \\
\hline 10 & 14 & 109 & 90 & 38 & 99 & 37 & 0 \\
\hline 10 & 14 & 163 & 90 & 97 & 77 & 20 & 3 \\
\hline 10 & 14 & 95 & 90 & 46 & 0 & 0 & 54 \\
\hline
\end{tabular}

Studies of the Massachusetts General Hospital. The overall anaesthetic management of these patients was left to the discretion of the attending anaesthesiologist; all patients' tracheas were intubated. Monitoring consisted of a precordial or oesophageal stethoscope, electrocardiogram, oscillometric or direct arterial blood pressure, temperature, inspired oxygen, and expired carbon dioxide. An adult disposable peripheral pulse oximeter probe (Nellcor, C-25) was placed on a finger or toe and a second oximeter probe, modified by taping the flexible piece of aluminum from an operating room mask to the back of a finger probe and then bending it into a $U$ shape such that the photo detector and photo emitter were opposite each other, was placed on the tongue. ${ }^{3}$ The study period began after both sensors were applied. A simultaneous recording was made of both peripheral and tongue oximeter saturation (two Nellcor N100 monitors and N9000 recorders) and heart rate. Data analyzed included only time intervals when both oximeters were placed so as not to bias data in favour of one oximeter location. An observer was present throughout each case to record factors which affected the pulseoximeter and to mark the tracings. Arterial blood gases were obtained from those patients with indwelling arterial catheters. Some patients were studied on more than one occasion.

Data collected included the age, weight, percent surface injury, time of usable monitoring, i.e., time free of motion or electrocautery artifact, time where both sites were functional, only one site was functional, or neither site was functional. A satisfactory recording was assumed when the heart rate from the oximeter was within several beats of the heart rate observed from the electrocardiogram. Baseline oxygen saturation values were compared using a paired Student's t test. For comparison purposes the total time of monitoring was recorded on both simultaneous strip charts and comparison was made between the two simultaneous recordings.

\section{Results}

Ten patients were studied on 15 occasions; one patient was studied three times and another on four occasions. The mean $( \pm S D)$ age of the patients was $7.5 \pm 4.5 \mathrm{yr}$ (range $2-16 \mathrm{yr}$ ), the mean weight $31.4 \pm 13.7 \mathrm{~kg}$ (range 15-53 $\mathrm{kg}$ ), and percent surface area burn $56 \pm 21 \%$ (range 19$90 \%$ ). A total of 1992 min was monitored; the mean ( $\pm \mathrm{SD}$ ) total of monitored anaesthesia time was $133 \pm 43$ $\mathrm{min}$. Both monitoring sites functioned simultaneously $47 \%$ of the time; the lingual but not the peripheral site functioned $28 \%$ of the time; only a peripheral and not the lingual site functioned $22 \%$ of the time; neither site functioned $3 \%$ of the time. Either lingual, peripheral, or both oximeter sensors functioned for $97 \%$ of the anaesthesia time studied (Table). The tongue oximeter provided a total of $563 \mathrm{~min}$ more monitoring time than the peripheral sites. Simultaneous saturation recordings obtained at baseline, demonstrated a slightly lower but not statistically different lingual $(97 \%$ ) than a peripheral site value $(99 \%)$. Both sites provided data consistent with the six arterial blood gas analyses, all of which showed a $\mathrm{PaO}_{2}$ high enough to saturate haemoglobin at $>97 \%$. Two episodes of desaturation were observed; one was diagnosed by the tongue oximeter but not the peripheral oximeter because it occurred when there was interference on the peripheral oximeter caused by the electrocautery; the second was simultaneously diagnosed by both oximeter probes. Although no blood gases were obtained during these events because of their transient nature, the patients both exhibited darkening of blood in the surgical field and 
cyanosis. There was one episode of severe hypotension where neither oximeter probe functioned. There were two cases which had such profound peripheral vasoconstriction that the peripheral oximeter sensor never functioned despite attempts at application on all four extremities. There was one case where we were unable to make the tongue sensor function after the patient was turned prone.

The most common cause of failure (95\%) during peripheral oximetry after initial successful application, was artifact caused by electrocautery; of particular interest was the observation that lingual oximetry was minimally affected during electrocautery despite as many as three electrocautery units being utilized simultaneously. If a patient was not completely paralyzed with neuromuscular blocking agents, the tongue was observed to quiver if the patient was lightly anaesthetized; this resulted in both heart rate and saturation artifact. Neuromuscular blockade was utilized for all patients and this artifact was only noted at the end of most cases or when neuromuscular blockade was wearing off or reversed.

\section{Discussion}

Pulse oximetry has clearly demonstrated efficacy during the anaesthetic management of paediatric surgical cases. ${ }^{1,2}$ Paediatric patients with extensive thermal injuries often require complex anaesthetic management because of the massive fluid shifts, blood loss, the altered pharmacology, sepsis mediated cardiovascular effects, and the sheer extent of tissue destruction. ${ }^{4-6}$ The clinical evaluation of oxygenation may be particularly difficult to assess because the nail beds may be stained with silver nitrate, tissues are massively edemetous, and the face is frequently bandaged. ${ }^{7}$ Assessing the colour of the oral mucosa and the blood shed during the procedure are often the only means of clinically estimating oxygenation. Pulse oximetry may occasionally be very difficult to obtain because of impaired blood flow to digits due to the injury and swelling as well as compromised circulation secondary to sepsis, hypovolaemia, vasoconstriction, or stained nail beds interfering with the oximeter sensor. ${ }^{7}$ Even when a pulse oximeter is satisfactorily applied to digit, nose, or ear, the information it may provide is often lost during the nearly constant electrocautery used during excision and grafting procedures. Tongue oximetry has been successfully utilized as a monitoring adjunct during the anaesthetic management of children having cardiac surgical procedures under profound hypothermia. This study and the study of paediatric cardiac surgical patients demonstrate that the tongue may be less susceptible to vasoconstriction than more conventional sites. ${ }^{3}$

Our results clearly demonstrate that the tongue is a reasonable alternative location for a pulse oximeter probe which provides data comparable to more conventional sites. In our study, the tongue was the only functional site in two patients with $90 \%$ surface area burn injuries. An additional observed clinical benefit was that the majority of electrocautery artifacts were eliminated; the mouth apparently prevents a radiofrequency artifact, perhaps either by conducting the interfering electrons away from the tongue or by the distance from the site of electrocautery. During the surgical excision of thermally damaged tissue it was common to have two and occasionally three simultaneous electrocautery units in use. We observed some electrocautery artifact with the tongue oximeter; however, there was much less interference, i.e., when the baseline value was decreased by the electrocautery, the value was depressed to a lesser degree and returned to accurate values more rapidly. We could not ascertain why on some occasions when using the tongue location there was no electrocautery artifact with three concurrent electrocautery units while on other occasions a single electrocautery unit resulted in small, brief, desaturation artifacts. This inconsistency may be related to position of the oximeter probe within the oral cavity.

Although we did not specifically assess the accuracy of tongue oximetry, our clinical trial does demonstrate that tongue oximetry is clearly a reasonably accurate adjunct to conventional peripheral monitoring sites. This conclusion is strengthened by the diagnosis of at least one desaturation event obscured on the conventional oximeter probe by concurrent electrocautery artifact.

Tongue oximetry is associated with a number of technical problems which require specific attention in order to provide reasonable data. The probe must be positioned after tracheal intubation and is best applied after placement of an oral temperature probe and oesophageal stethoscope. The probe can be dislodged easily if the patient is repositioned, with placement of an oral temperature probe and oesophageal stethoscope, and especially when the patient is turned prone. (This accounted in part for the $22 \%$ failure rate.) Once the patient is turned prone, it is much more difficult to achieve proper tongue application as occurred in one patient who only had peripheral oximetry. Tongue movement, especially when the intensity of neuromuscular blockade is reduced, produces movement artifact: tongue quivering may mimic tachycardia. It was our impression that this probe was more easily placed and maintained in the smaller patients. When a peripheral oximeter sensor cannot be placed, an alternative site such as the tongue may be substituted until peripheral perfusion is restored.

Two additional potential problems may be associated with tongue oximetry using disposable probes: electrical safety and absorption of the acrylic glue on the sensor. The latter would not appear to be a concern since such adhesives are commonly used for dental restorations and as 
a means of patch testing for common allergens. ${ }^{8-10}$ This unit incorporates a patient isolation board which, (1) provides electrical isolation between the patient sensor and the system electronics, (2) provides isolated power for patient side electronics such as the pre-amp circuit and the light emitting diode (LED's), (3) drives and controls both red and infrared LED's, (4) reads and transmits the calibration resistor to processor, and (5) notifies the processor of low LED conditions. This means that should patient isolation break down, the unit will cease to function and no oximetry readings would be available. Therefore, the complete isolation provided by the patient isolation board would appear to eliminate most electrical safety concerns. Using a disposable probe, however, may present one other electrical concern; should the LED circuitry not be fully sealed when placed in the wet mouth, the anode and cathode of each LED may become conductively bridged to each other. This may cause current to be directed from one LED to the other. However, with normal operation, each LED is illuminated for $25 \%$ of the time and $50 \%$ of the time both are off. With this duty cycle (25\%) the accidental electrical bridging would cause the LED's to become dimmer. The maximal voltage delivered to the LED's would be 1.3 volts at $1432 \mathrm{hz}$ resulting in a maximum power of 32 milliwatts and maximum heat generation of $1^{\circ} \mathrm{C}$.

A solution to concerns for absorption of acrylic glue and electrical safety could be obviated by substituting the reusable Nellcor Oxibond sensor for the lingual site; this sensor has no adhesive applied to the sensor and is completely sealed, thereby eliminating the potential for current leakage or short circuit.

In summary, this clinical study demonstrates the efficacy of tongue oximetry in critically ill patients with severe thermal injury. Tongue oximetry is a reasonable adjunct but not a substitute for peripheral oximetry. Tongue oximetry is less susceptible but not totally free of electrocautery artifact. Tongue oximetry may provide the only viable alternative for selected patients with the most extensive injury who have oedema, profound vasoconstriction, or discolored nail beds which prevent successful application of standard peripheral oximetry. Its use is limited, however, to patients whose tracheas are intubated, and who are paralyzed. Therefore, it is of little use during induction, emergence, or recovery from anaesthesia.

\section{References}

1 Coté CJ, Goldstein EA, Coté MA, Hoaglin DC, Ryan JF. A single-blind study of pulse oximetry in children. Anaesthesiology 1988; 68: 184-8.

2 Coté CJ, Rolf N, Liu LMP, et al. A single-blind study of combined pulse oximetry and capnography in children. Anaesthesiology 1991; 74: 980-7.

3 Jobes DR, Nicolson SC. Monitoring of arterial hemoglobin oxygen saturation using a tongue sensor. Anesth Analg 1988; 67: 186-8.

4 Fein A, Leff A, Hopewell PC. Pathophysiology and management of the complications resulting from fire and the inhaled products of combustion: review of the literature. Crit Care Med 1980; 8: 94-8.

5 Demling RH. Burns. N Engl J Med 1985; 313: 1389-98.

6 Martyn J. Clinical pharmacology and drug therapy in the burned patient. Anaesthesiology 1986; 65: 67-5.

7 Coté CJ, Goldstein EA, Fuchsman WH, Hoaglin DC. The effect of nail polish on pulse oximetry. Anesth Analg 1988; 67: 683-6.

8 Fischer T, Maibach HI. Easier patch testing with TRUE test. J Amer Acad Dermatol 1989; 20: 447-53.

9 Mojon P, Hawbolt EB, MacEntee MI, Belser UC. Maximum bond strength of dental luting cement to amalgam alloy. J Dent Res 1989; 68: 1545-9.

10 Capersen IVAR. Residual acrylic adhesive after removal of plastic orthodontic brackets: a scanning electron microscopic study. Am J Orthod 1977; 71: 637-50. 